\title{
The Design and Development of Sit to Stand Trainer for the Elderly
}

\author{
Sairag SA-ADPRAI ${ }^{1}$ and Bunyong RUNGROUNGDOUYBOON ${ }^{2, *}$ \\ ${ }^{1}$ Excellence Center in Creative Engineering Design and Development, Department of Sport Science and \\ Sport Development, Faculty of Allied Health Sciences, Thammasat University, \\ Pathum Thani 12120, Thailand \\ ${ }^{2}$ Excellence Center in Creative Engineering Design and Development, Department of Mechanical \\ Engineering, Faculty of Engineering, Thammasat University, Pathum Thani 12120, Thailand
}

Received: 21 October 2018, Revised: 26 January 2019, Accepted: 15 February 2019

('Corresponding author's e-mail: rbunyong@engr.tu.ac.th)

\begin{abstract}
Strengthening exercise for lower limbs is required in elderly. Repeated sit to stands could improve lower limbs strength, reduce limitations, and fall. The researchers developed a Sit to Stand Trainer, a device that assists and offers variable levels of weight support for users to stand. It was validated by comparing the kinematics and the kinetics between 2 experimental conditions; the movement that was assisted by Sit to Stand Trainer (STST) and the natural movement that was unassisted by Sit to Stand Trainer (No STST). This study is an Experimental Design using Pearson Correlation Coefficient. The time span of the observed movement was $2.5 \mathrm{~s}$ for all trials. The results in kinematics showed significant similarity in trunk, hip, knee, ankle angles and angular velocities including speed and distance of head between No STST to STST $(\mathrm{P}=0.000)$. However, in kinetics, the maximum of VGRFs showed significant decrease in STST compared to No STST $(\mathrm{P}=0.000)$. This represent that this device produces natural movement and speed. It also supports and helps to reduce the body weight that contacted to the ground in order to stand up easier. Thus, therapists could possibly consider this device for training in clinical practice. This research was studied within 6 weeks into training with Sit to Stand Trainer. This part of the study is a Quasi-Experimental Designs using Paired Samples T-tests. The results of the T-tests were compared before and after the training. The results showed a significant improvement in physical outcomes measurement tests; Berg Balance Scale $(\mathrm{P}=0.000), 30$-second Chair Stand $(\mathrm{P}=0.001)$ and 4meter Gait Speed $(\mathrm{P}=0.000)$ among the elderly.
\end{abstract}

Keywords: Exercise machine, Sit to stand trainer, Biomechanics of sit to stand, Elderly

\section{Introduction}

Muscle weakness in lower limbs leads to poor functional abilities, increased risk of fall, recurrent falls [1] and mortality [2]. Strengthening exercise for lower limbs is required in elderly. Repeated sit to stands without assistance from the upper limbs could improve lower limbs strength and reduce functional limitations $[3,4]$. In clinical practice, sit to stand training among frail elderly is performed by using arms or being supported by 1 or 2 therapists [5-7]. However, the movement is slow as compared to normal movement and physically fatigue for therapists [7]. Nowadays, various medical devices are designed to assist elderly and patients in clinical practice [8]. Nevertheless, these devices are unnatural of movement and speed. [9-11]. Additionally, several devices are not adequately and scientifically tested in kinematic, kinetic, and physical outcome measurement after a long period of training. Therefore, therapists feel hesitated to use due to a concern about their unnatural movement and speed which may promote injury. Thus, the researchers have developed a Sit to Stand Trainer, a device that helps to produce a natural movement and speed that can assist users to stand with variable levels of weight support. 


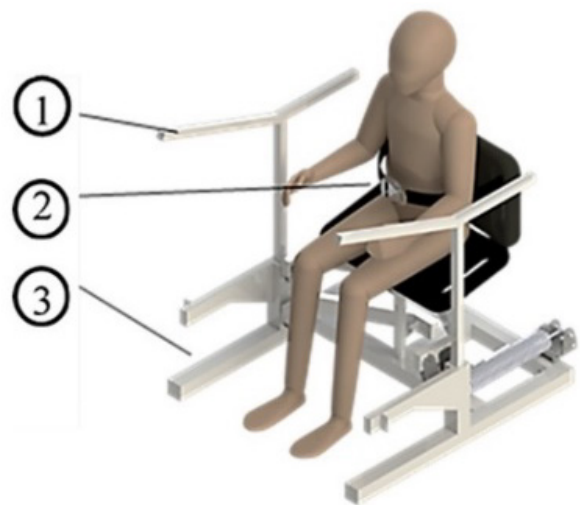

(a)

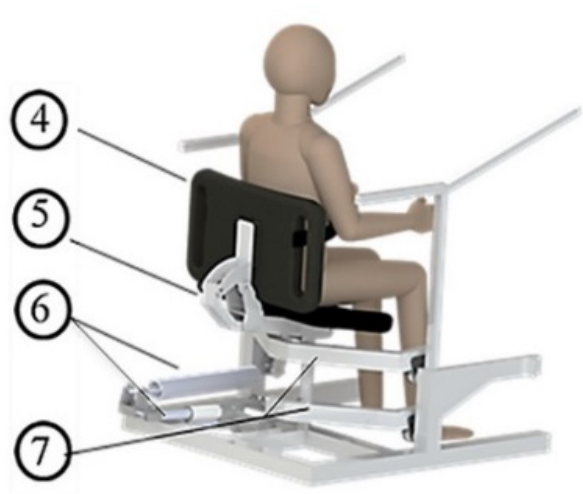

(b)

Figure 1 Mechanical design of the Sit to Stand Trainer (a) 1) armrest, 2) safety belt, 3) base frame. (b) 4) trunk support, 5) chair mechanism, 6) tension spring and actuator, 7) parallel links.

\section{The development of sit to stand trainer}

The new design of Sit to Stand Trainer (Figure 1), a device that assists user to stand, can support between $20-50 \mathrm{~kg}$. The mechanism of the Sit to Stand Trainer is the parallel links and chair mechanism. The parallel links may push the chair mechanism pivot from the sitting to standing position (Figure 2). We can adjust the weight support by prolonging the linear actuator to stretch the spring. The longer the spring, the more weight it can support. The linear actuator could prolong by using a remote-control. The Sit to Stand Trainer has 9 levels; the first level assists $20 \mathrm{~kg}$ and increases every $4 \mathrm{~kg}$ in each level. Accordingly, we can calculate and adjust the support level depending on the users' ability and their body weight. The safety of factor of Sit to Stand Trainer is 7. The specification of the linear actuator is $6,000 \mathrm{~N}$ load capacity and $80 \mathrm{~mm}$ stroke length. The physical data of the spring are $6 \mathrm{~mm}$ of wire-diameter, 45 $\mathrm{mm}$ of outer diameter, $270 \mathrm{~mm}$ length and the spring rate $(\mathrm{k})$ is $6.5 \mathrm{~N} / \mathrm{mm}$.

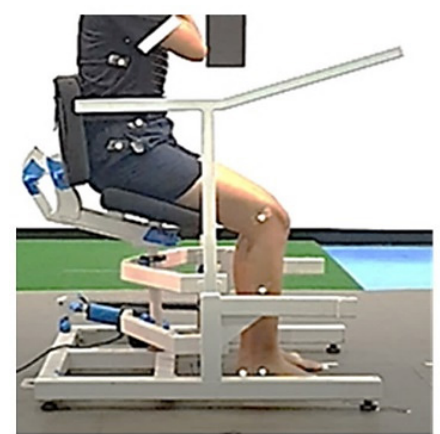

(a)

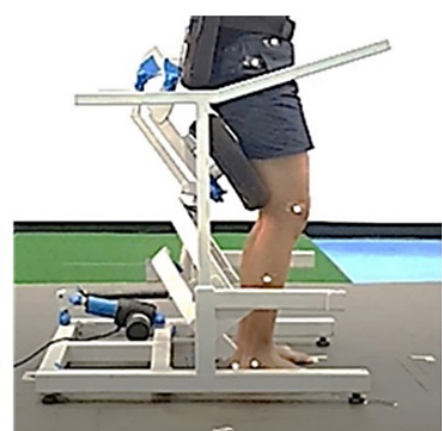

(b)

Figure 2 Parallel links and chair mechanisms from (a) sitting position to (b) standing position. 
http://wjst.wu.ac.th

This research validated the device by comparing both kinematics and kinetics between 2 experimental conditions; the movement that was assisted by Sit to Stand Trainer experimental condition (STST) and the natural movement that was unassisted by Sit to Stand Trainer experimental condition (No STST). The was done to see if it could be considered to be used in clinical practice and also to evaluate the physical outcome measurement tests after 6 weeks of training with the Sit to Stand Trainer among the elderly. This research was approved by the Ethics Review Sub-Committee for Research Involving Human Research Subjects of Thammasat University, No.3, protocol number 040/2561. All the subjects signed the informed consent forms.

\section{Device validation}

\section{Methods}

Subjects

Four adults (2 males and 2 females), no musculoskeletal and neurological impairment (age $21.5 \pm$ 2.38 years, body mass index $22.3 \pm 2.1$, weight $63.13 \pm 8.78 \mathrm{~kg}$, height $168.5 \pm 6.4 \mathrm{~cm}$ ) participated in this study. The researchers sent information sheets to the dweller individually in the communities nearby Thammasat University to promote, invite, and give the details about this study. The participants, who were supervised in this study, spent approximately $1 \mathrm{~h}$ at Faculty of Allied Health Sciences, Thammasat University. The data were collected by the physiotherapists and sport scientists.

\section{Experimental protocol and data collection}

Kinematics and kinetics patterns were recorded while all the subjects performed sit to stand under 2 experimental conditions (No STST and STST).

NO STST: The subject stood on the standing area of the Sit to Stand Trainer. The researcher helped to adjust the height of the seat to reach at the level of the subject's knees height. Then, the subject sat down. However, in this experimental condition, the mechanism of the Sit to Stand Trainer did not move to assist the subject who did not fasten the safety belt. Therefore, the subject could perform natural sit to stand. The subject was instructed to stand and sit down comfortably and was asked to perform the sitting and standing position.

STST: The subject stood on the standing area of the Sit to Stand Trainer. The subject fastened the safety belt. Then, he was asked to sit down. When subject was ready, the researcher adjusted the support level at $50 \%$ of the body weight. The subject was instructed to stand and sit down comfortably and was asked to perform the sitting and standing position.

The subject performed 5 times in each experimental condition (all subjects were convinced to practice 3 times of sit to stand movement before each experimental condition). The beginning of sit to stand movement could not be controlled as it depended on subjects' nature of movement. Thus, the time of movement was completed by a time marker, which was designed when the hip marker touched half way between sitting and standing posture. The time span of the movement was $2.5 \mathrm{~s}$ (1.25 s prior and 1.25 $\mathrm{s}$ post to time marker). The mean and the standard deviations from 4 subjects ( 5 trials in each subject) under No STST and STST were calculated for angles, angular velocities, speed and distance of head including vGRFs.

\section{Instrumentation}

Kinovea (0.8.15) is a software used as a tool for movement analysis of the right lower limb, trunk and head. The reflective markers were placed over selected anatomical joints and segment angles (Figure 3) and a single AMTI force plate (AMTIOR-6-5-1000) imbedded in the floor was used to record vGRFs under the feet. Force data were sampled at $100 \mathrm{~Hz}$ which is appropriate for standing posture [12]. 


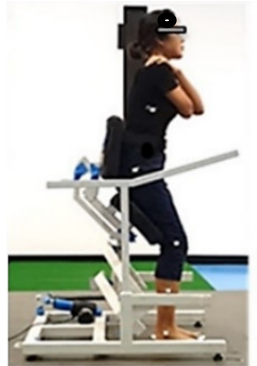

(a)

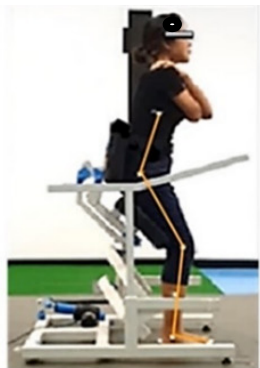

(b)

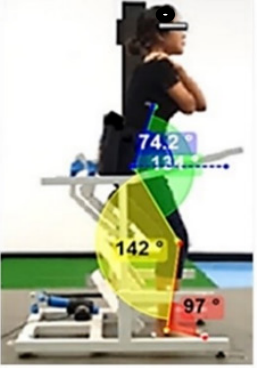

(c)

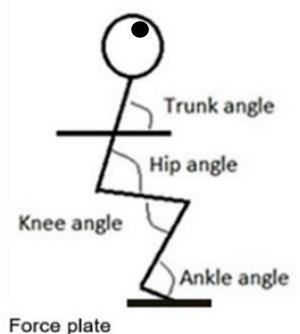

(d)

Figure 3 Represents (a) locations of the markers in the sagittal plane, (b) lines linked between markers, (c) degree of each angle (trunk segment angles are relative to horizontal plane), (d) drawing of angles (trunk, hip, knee and ankle joint angles).

\section{Statistics analysis}

The pearson correlation coefficient was calculated to quantify similarity in kinematics (angles, angular velocities, speed and distance of head). Paired Samples T-tests was used to measure the differences in kinetics (vGRFs) between No STST and STST.

\section{Results and discussion in kinematics}

Table 1 presents the Pearson correlation coefficient values of angles comparing between No STST to STST of 4 subjects. This research shows a strong correlation for hip angle $(r=0.832)$, knee angle $(r=$ $0.978)$, ankle angle $(r=0.955)$ and a moderate correlation for trunk angle $(r=0.697)$ which all have a significant similarity of sit to stand movement patterns between No STST to STST at P $=0.000$. These results show that standing up with the Sit to Stand Trainer produces natural movement patterns without the limitation of lower limbs joints and trunk.

Table 1 Values of correlation coefficients quantifying similarity in kinematics (angles) of No STST to STST are given $(\mathrm{n}=4)$.

\begin{tabular}{ccl}
\hline Angle (deg) & corr. coeff $\mathbf{r}$ & P value \\
\hline Trunk & 0.697 & $0.000^{* *}$ \\
Hip & 0.832 & $0.000^{* *}$ \\
Knee & 0.978 & $0.000^{* *}$ \\
Ankle & 0.955 & $0.000^{* *}$ \\
\hline
\end{tabular}

**Correlation is significant at the 0.01 level (2-tailed).

As in the Figure 4(a) the first column shows movement patterns of No STST and the second column shows movement patterns of STST for 4 subjects. As in the Figure 4(b) the first column shows movement patterns of No STST and the second column shows movement patterns of STST for a representative subject in 5 repetitions. In the start phase of both experimental conditions, hip angle and knee angle were slightly bigger than perpendicular angle; while the trunk angle was slightly bigger than the perpendicular angle with the horizontal plane in sitting position. The rising phase of both experimental conditions resulted to a decreased in the trunk angle and hip angle. However, the knee angle 
http://wjst.wu.ac.th

increased (trunk and hip joint bent upward and forward and knee joint outstretched). The terminal phase of both experimental conditions; hip angle and knee angle increased almost to parallel with the vertical plane in standing position; while the trunk angle was approximately perpendicular to horizontal plane in standing position. Although, in both experimental conditions, in the start phase, the ankle angle was slightly bigger than the perpendicular angle and had a very slight decreased in the rising phase and terminal phase.

No STST<smiles>[TeH]</smiles>
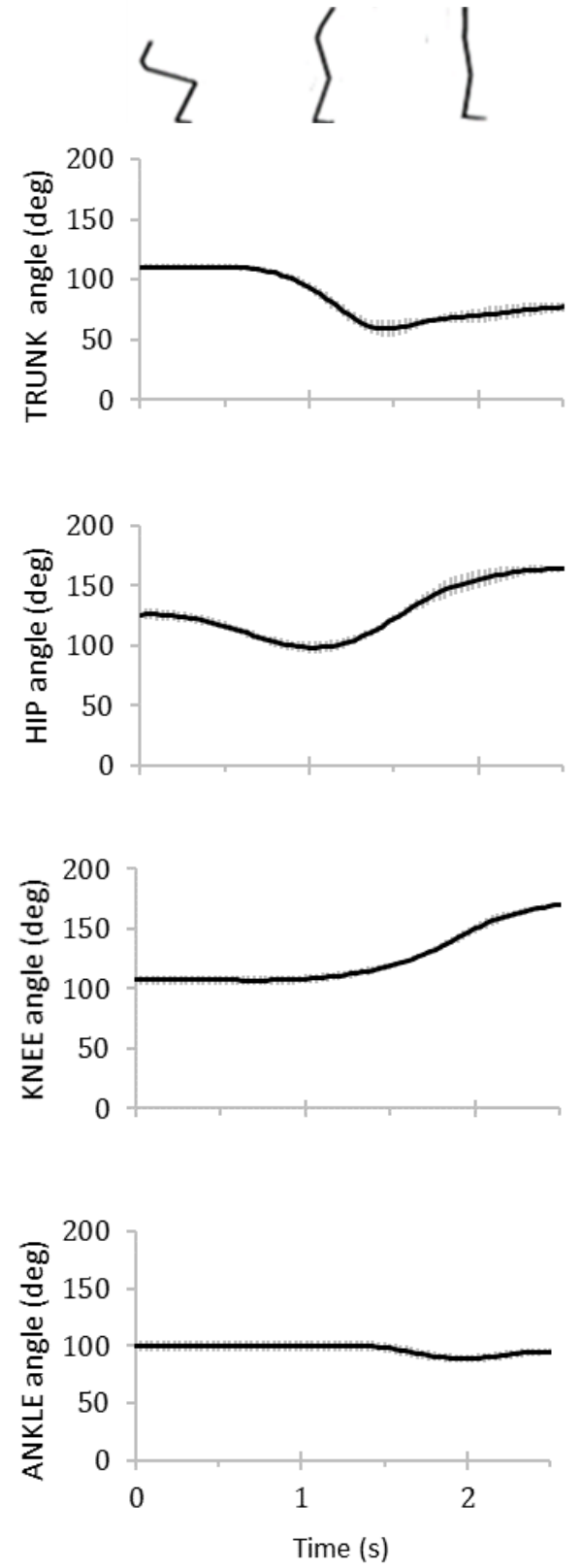

STST
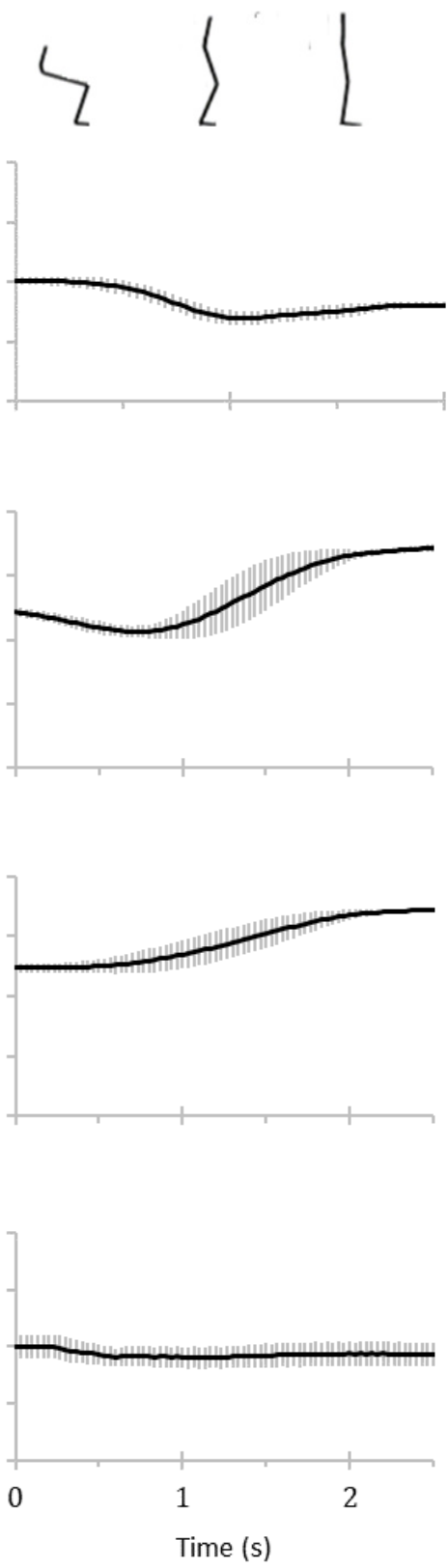
(a)

No STST
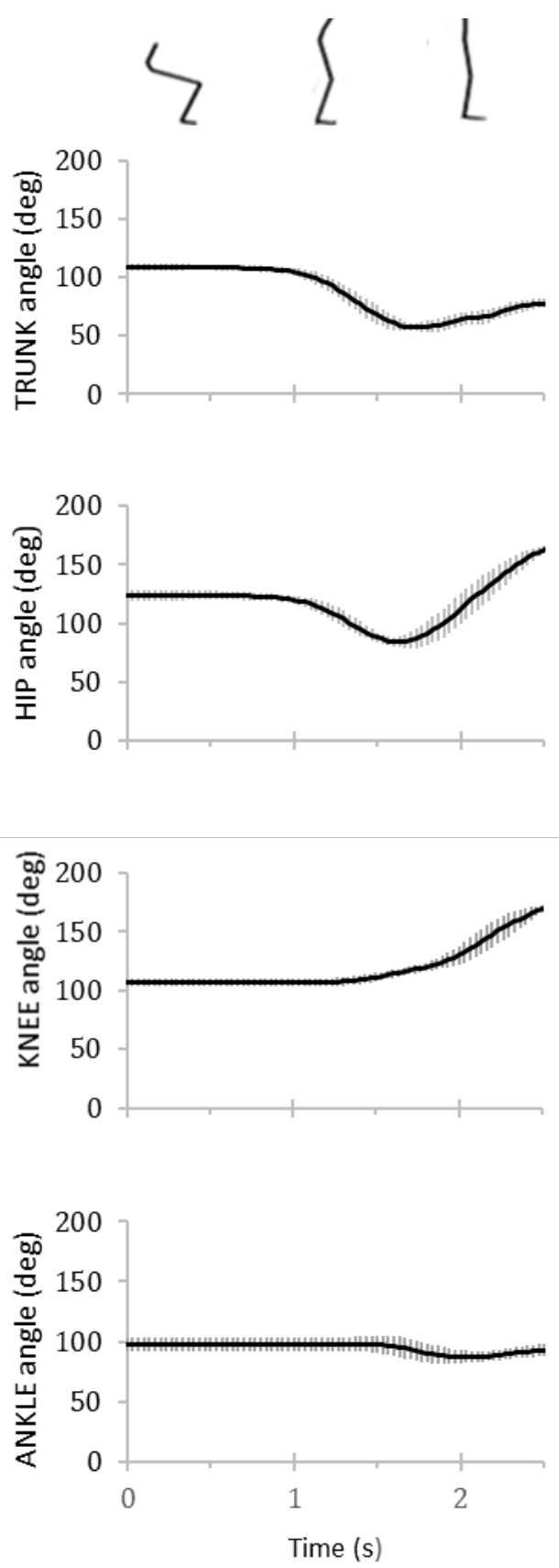

STST
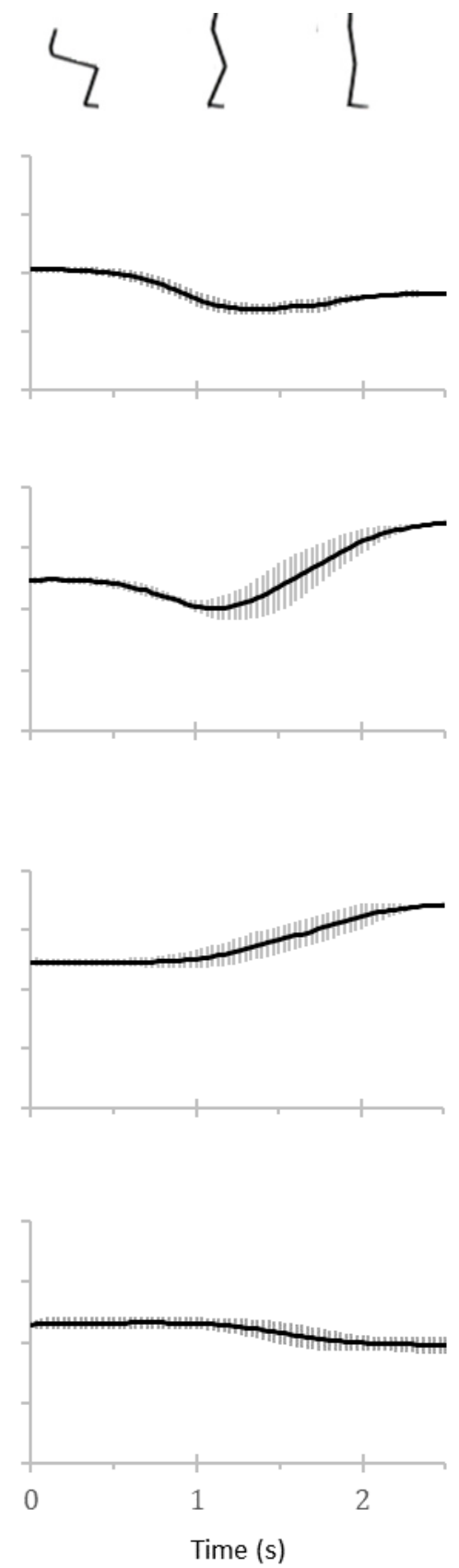

(b)

Figure 4 (a) Trunk, hip, knee, ankle joint angles of No STST and STST (mean and standard deviations of 4 subjects), (b) Trunk, hip, knee, ankle joint angles of No STST and STST (mean and standard deviations for a representative of 5 repetitions). 
http://wjst.wu.ac.th

Table 2 presents the Pearson correlation coefficient values comparing the angular velocities between No STST to STST of 4 subjects. However, this study shows moderate correlation for trunk angular velocity $(r=0.569)$ and hip angular velocity $(r=0.662)$ and shows strong correlation for knee angular velocity $(\mathrm{r}=0.927)$ and ankle angular velocity $(\mathrm{r}=0.878)$. These are all significantly similar in angular velocities (trunk, hip, knee and ankle) between No STST to STST at P $=0.000$.

Table 2 Values of correlation coefficients quantifying similarity in kinematics (angular velocities) of No STST to STST are given $(n=4)$.

\begin{tabular}{ccl}
\hline Angular velocity $(\mathbf{d e g} / \mathbf{s})$ & corr. coeff $\mathbf{r}$ & P value \\
\hline Trunk & 0.569 & $\mathbf{0 . 0 0 0 * *}$ \\
Hip & 0.662 & $\mathbf{0 . 0 0 0 * *}$ \\
Knee & 0.927 & $\mathbf{0 . 0 0 0 * *}$ \\
Ankle & 0.878 & $\mathbf{0 . 0 0 0 * *}$ \\
\hline
\end{tabular}

**Correlation is significant at the 0.01 level (2-tailed).

As in the Figure 5(a) the first column shows angular velocities of No STST and the second column shows angular velocities of STST for 4 subjects. As in the Figure 5(b) the first columns show angular velocities of No STST and the second columns show angular velocities of STST for a representative subject in 5 repetitions. In the start phase of both experimental conditions, the velocity in all angles were slow. Angular velocity of trunk, hip and ankle started to move to an anterior direction, in contrast to angular velocity of knee which started with a posterior direction. In the rising phase of both experimental conditions, the velocity in all angles raised faster. Angular velocity of trunk, hip and ankle changed to a posterior direction; however, angular velocity of knee still moved to a posterior direction. In the terminal phase of both experimental conditions, velocity in all angles tended to reach their peak in the posterior direction and then slightly moved to an anterior position while completely standing. 
No STST
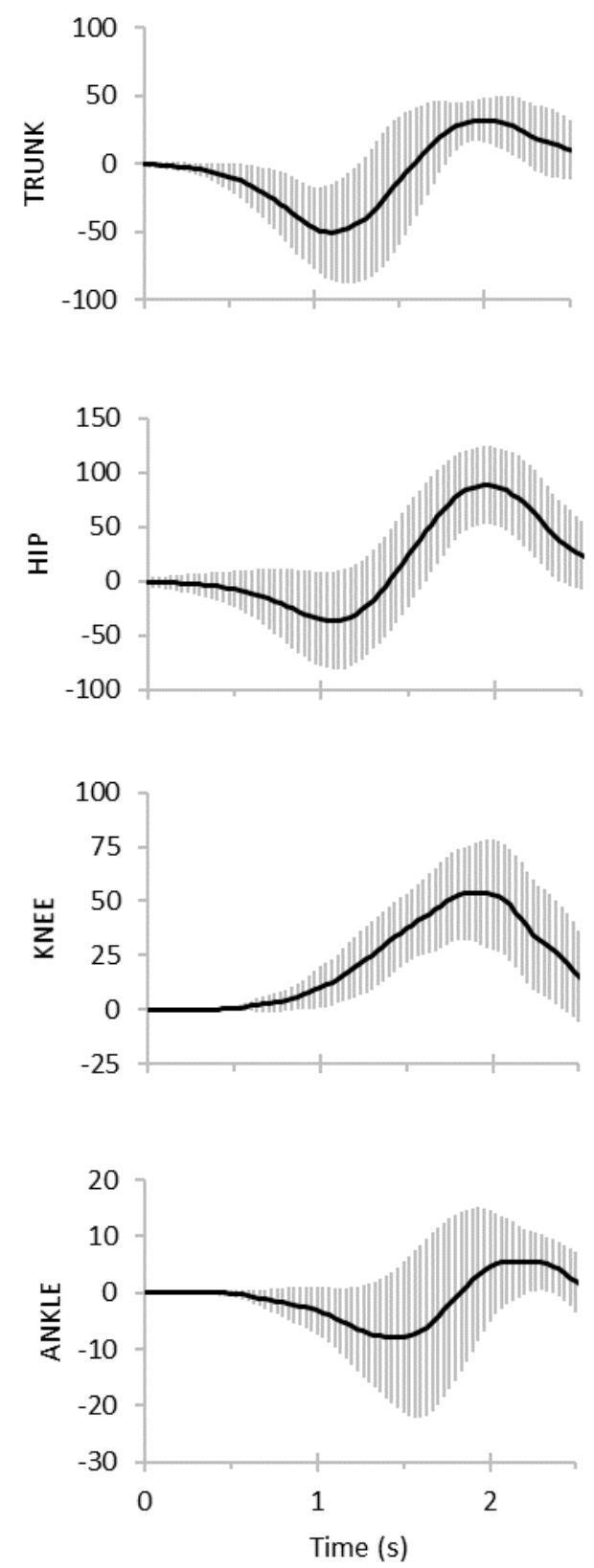

STST
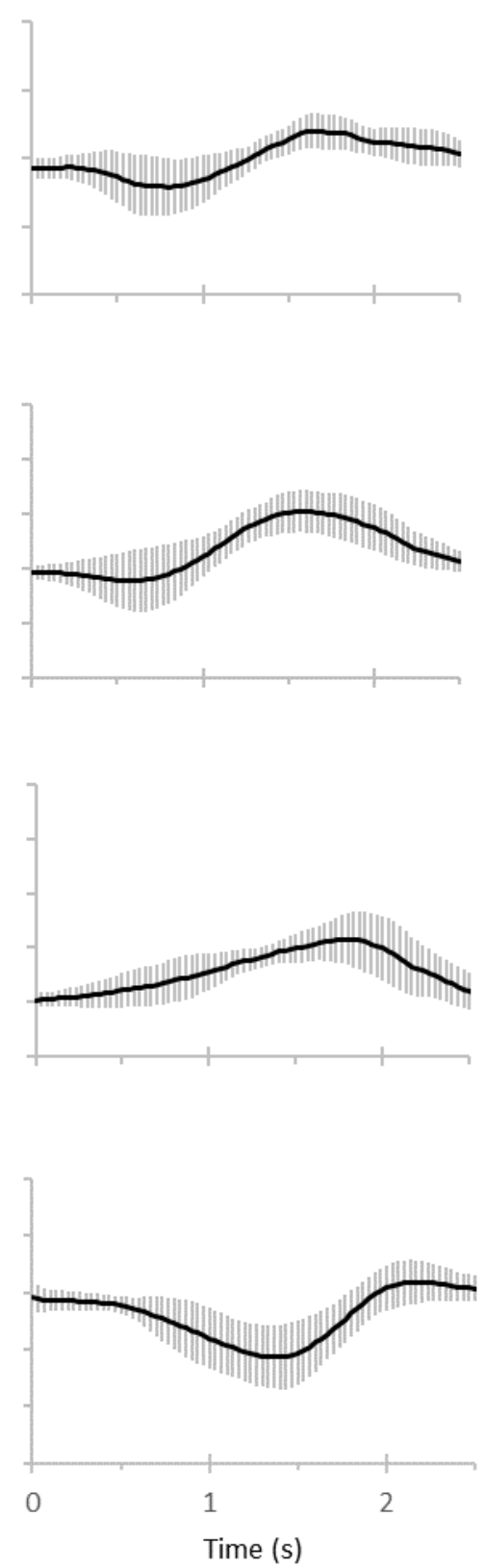

(a) 
No STST
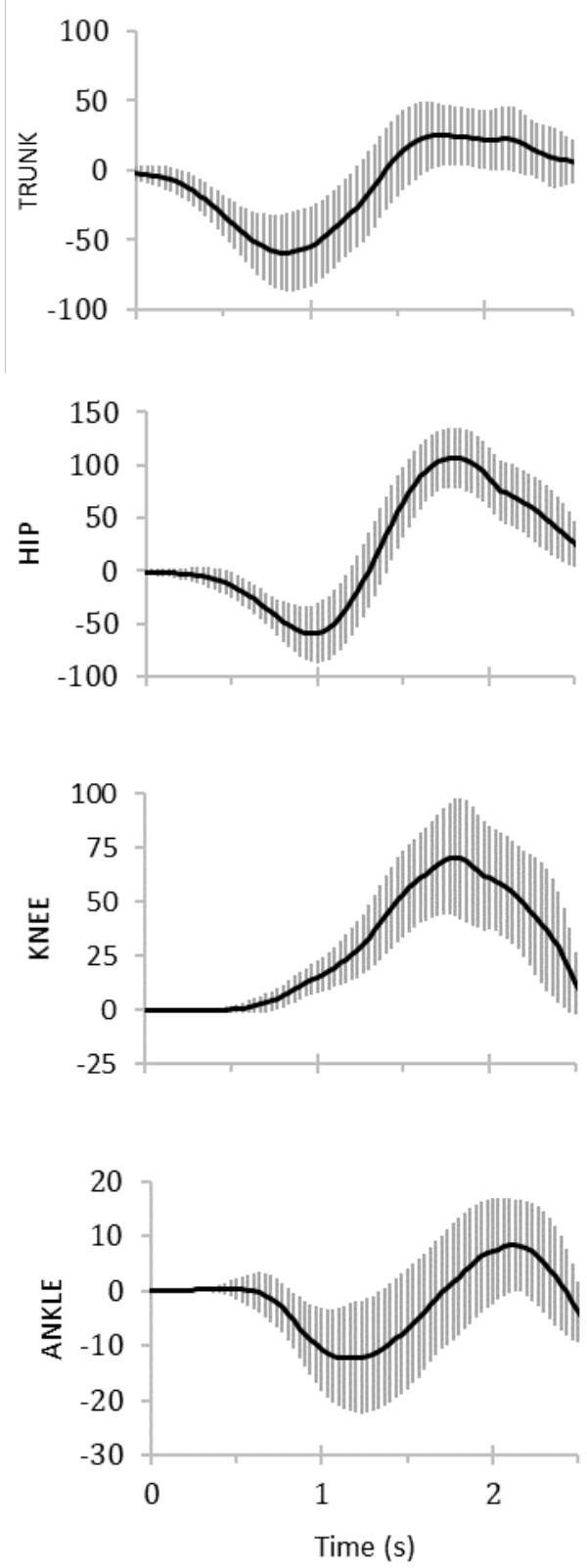

STST
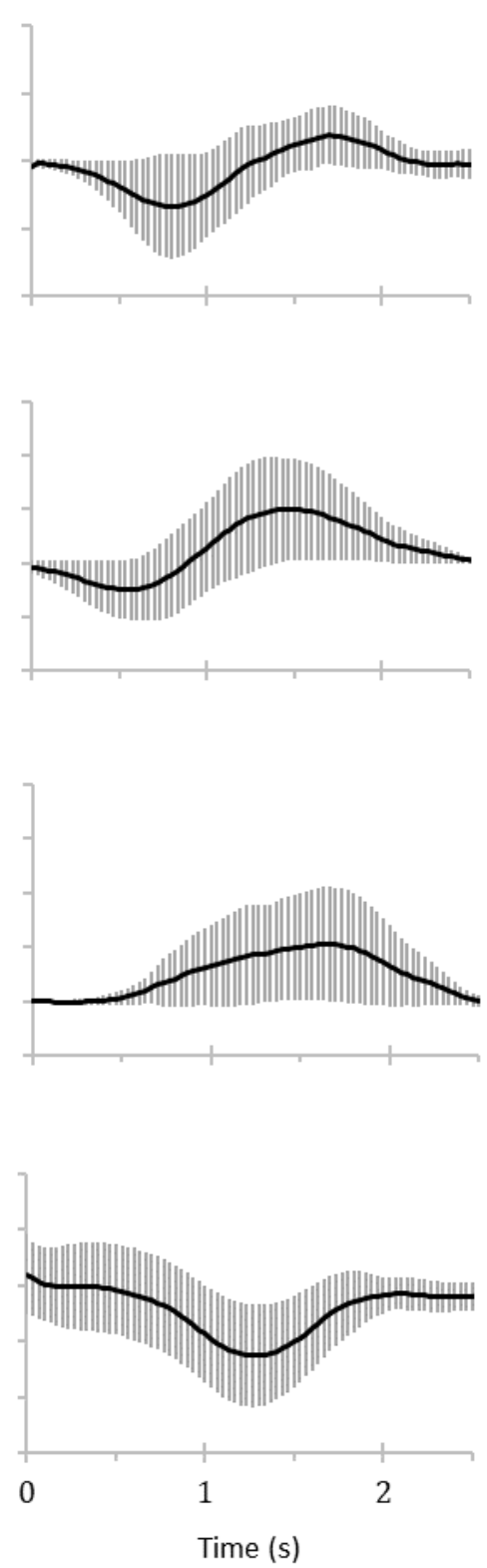

(b)

Figure 5 (a) Trunk, hip, knee and ankle joint angular velocities of No STST and STST (mean and standard deviations of 4 subjects), (b) Trunk, hip, knee and ankle joint angular velocities of No STST and STST (mean and standard deviations for a representative of 5 repetitions). 
http://wjst.wu.ac.th

Table 3 presents the Pearson correlation coefficient values comparing between No STST to STST of 4 subjects which shows moderate correlation in speed of head $(\mathrm{r}=0.635)$ and shows strong correlation in distance of head $(\mathrm{r}=0.971)$. It is significantly similar in speed and distance of head between No STST and STST at $\mathrm{P}=0.000$.

Table 3 Values of correlation coefficients quantifying similarity in kinematics (speed and distance of head) of No STST and STST $(n=4)$.

\begin{tabular}{ccl}
\hline Head & corr. coeff $\mathbf{r}$ & P value \\
\hline Speed of head $(\mathrm{m} / \mathrm{s})$ & 0.635 & $\mathbf{0 . 0 0 0 * *}$ \\
Total distance of head $(\mathrm{m})$ & 0.971 & $\mathbf{0 . 0 0 0 * *}$
\end{tabular}

**Correlation is significant at the 0.01 level (2-tailed).

As in the Figure 6(a) the first column shows speed and distance of head of No STST and the second column shows speed and distance of head of STST for 4 subjects. As in the Figure 6(b) the first column shows speed and distance of head of No STST and the second column shows speed and distance of head of STST for a representative subject in 5 repetitions. The speed of head in both experimental conditions started rising in the start phase and raised highest in the second phase and dropped in the terminal phase. In the rising phase of No STST experimental condition, the speed of head raised higher than in STST experimental condition. Moreover, the distance of head in both experimental conditions was continuously raised from the start phase to the terminal phase. And the distance of head movement in the terminal phase of No STST was slightly raised higher than in the terminal phase of STST.

No STST
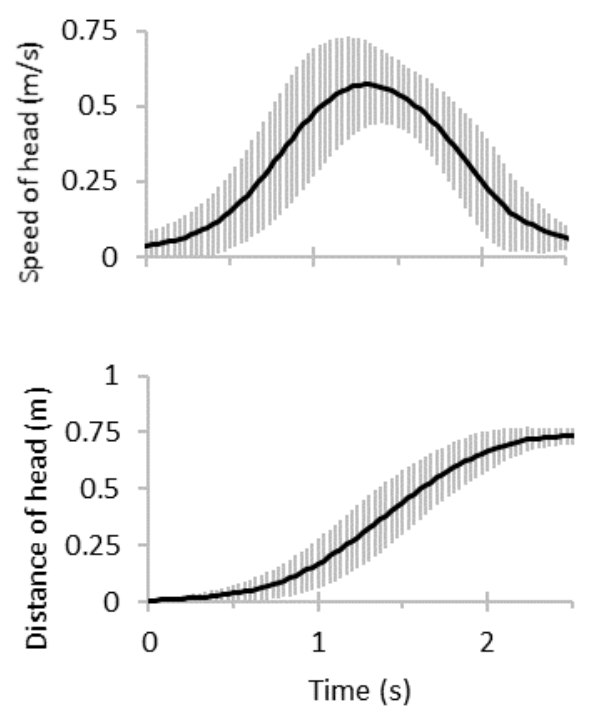

STST
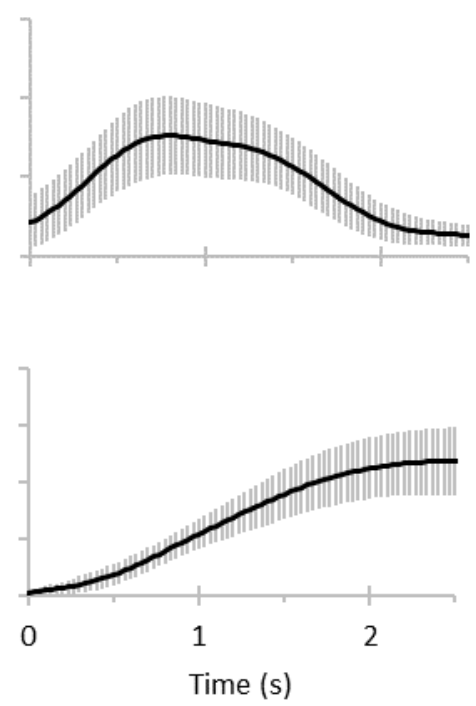

(a) 
http://wjst.wu.ac.th

No STST
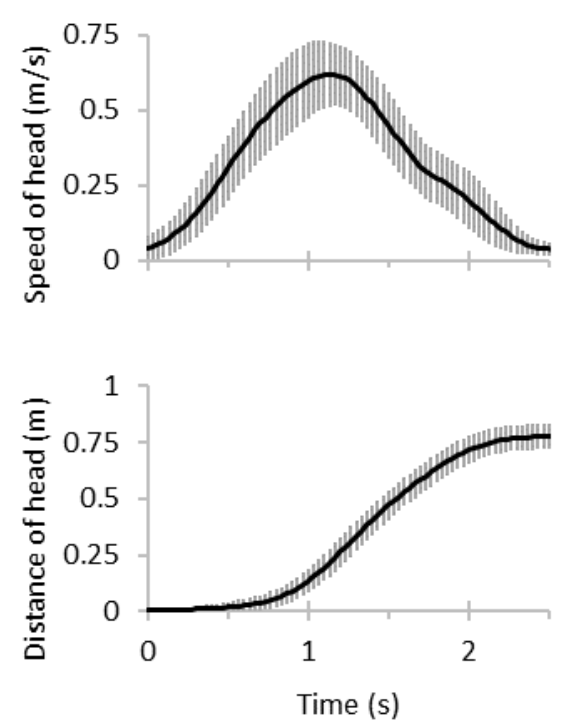

STST
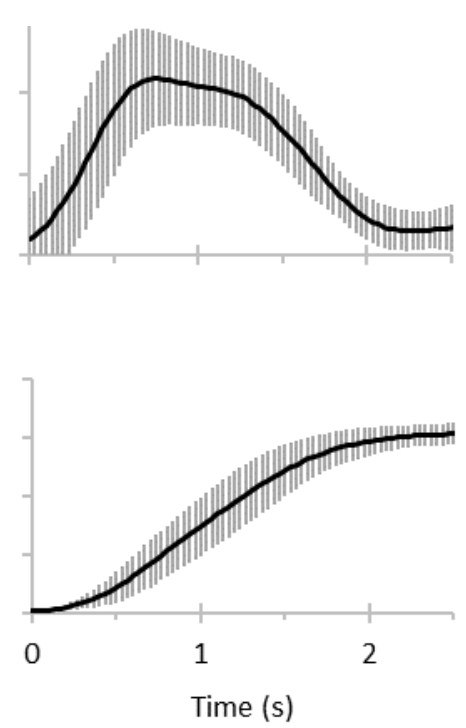

(b)

Figure 6 (a) Speed and distance of head of No STST and STST (mean and standard deviations of 4 subjects), (b) Speed and distance of head of No STST and STST (mean and standard deviations for a representative of 5 repetitions).

The kinematics between No STST and STST in this study are significantly similar. However, this study discusses 3 points; first, in No STST; trunk and hip angles were slightly smaller in the rising phase as compared to the STST. Second, in No STST; the velocity in all angles and the speed of head were slightly faster as compared to the STST. And third, in No STST; the distance of head movement was slightly longer as compared to the STST. The reason for this is in natural movement of sit to stand (No STST), the subjects probably have to use their force to keep balance and control their body center of mass momentum more than in the STST on which the subjects were dependent on the assisting device [13,14].

\section{Results and discussion in kinetics}

As in Table 4 shows the significant difference of the maximum of vGRFs between No STST and STST at $\mathrm{P}=0.007$ and shows the significant difference of mean values of rising vGRFs between No STST and STST at $\mathrm{P}=0.000$. Based on these results, the Sit to Stand Trainer can reduce the body weight that contacted to the ground during the start and rising phase which helps the users to stand up easier. This was noted as the start phase and the rising phase of sit to stand movement are the most difficult phases to stand up among elderly which is related to Quadricep and Hamstring muscles weakness [15]. 
http://wjst.wu.ac.th

Table 4 Means, standard deviation of maximum and mean of rising GRFs of all subjects as compared between No STST to STST $(n=4)$.

\begin{tabular}{cccccc}
\hline \multirow{2}{*}{ GRF (BW) } & \multicolumn{2}{c}{ No STST } & \multicolumn{2}{c}{ STST } & \multirow{2}{*}{ P value } \\
\cline { 2 - 5 } & Mean & SD & Mean & SD & \\
\hline Maximum & 1.09 & 0.02 & 0.99 & 0.05 & $\mathbf{0 . 0 0 7 *}$ \\
Mean of Rising & 0.22 & 0.31 & 0.17 & 0.28 & $\mathbf{0 . 0 0 0 *}$ \\
\hline
\end{tabular}

*Significant at $\mathrm{P} \leq 0.05$

As in the Figure 7(a) the first column shows vGRFs of No STST and the second column shows vGRFs of STST for 4 subjects. As in the Figure 7(b) the first column shows vGRFs of No STST and the second column shows VGRFs of STST for a representative in 5 repetitions. vGRFs were normalized by bodyweight $(\mathrm{BW})$. In No STST, it shows the maximum of vGRFs coinciding with the peak flexion in hip joint, like in normal of sit to stand movement pattern in which the maximum of vGRFs is approximately $10 \%$ above the body weight in the rising phase [16,17]. However, in STST, it shows smaller maximum of vGRFs and it also shows smaller in mean values of rising vGRFs as compared to No STST.

No STST

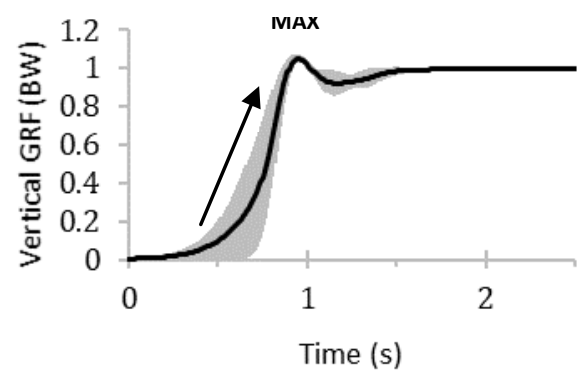

No STST

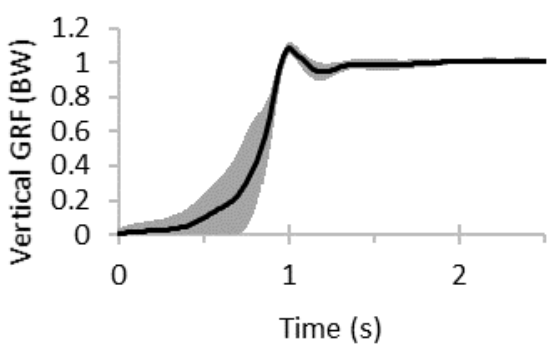

STST

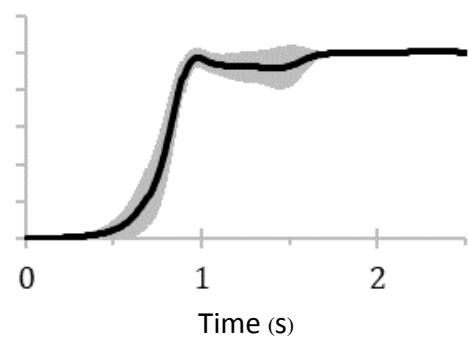

(a)

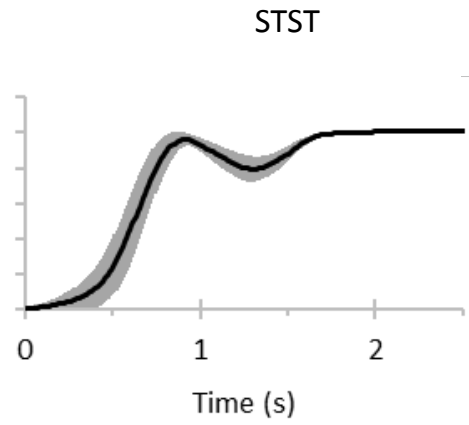

(b)

Figure 7 (a) GRFs of No STST and STST (mean and standard deviations of 4 subjects), (b) GRFs of No STST and STST (mean and standard deviations for a representative of 5 repetitions). 
http://wjst.wu.ac.th

\section{Physical outcome measurement tests evaluation}

\section{Methods}

Subjects

Twenty-seven older adults (14 males and 13 females), who have no musculoskeletal and neurological impairment (age $67.3 \pm 6.16$ years, body mass index $26.48 \pm 6.76$ weight $64.91 \pm 11.58$ kilograms, height $160.15 \pm 9.28$ centimeters) participated in this study. The researchers sent information sheets to the elderly individually in the communities nearby Thammasat University to promote, invite, and give the details about this study. The participants in this study spent 6 weeks at Romyen-Roongsin community, Pathumthani. All the participants performed the tests under the supervision by the physiotherapists and sport scientists who also collected the data. (Although this device has not been validated with elderly subjects since they are vulnerable persons, this device has been previously validated in biomechanics laboratory by healthy subjects. The results proved that it is safe and it produces natural movement and speed which can also support and help to reduce the body weight. Thus, the users can stand up easier which is safe, suitable, and supportable for the elderly).

\section{Experimental protocol}

The researchers delivered the Sit to Stand Trainers to the community's Multipurpose Hall. Then, the researchers collected the anthropometrics and health history. The subjects' physical outcome measurement data (4 m Gait Speed Test, 30 s Chair Stand Test, Berg Balance Scale (BBS), $15 \mathrm{~cm}$ Step Test) were also collected in 3 times. The first outcome measurement tests were collected 4 weeks before the training program (week -4). The second outcome measurement tests were collected before the first day of the training program (week 0). The third outcome measurement tests were collected after 6 weeks of training program (week 6). The six weeks of resistance and functional exercise program have been shown to be effective among elderly $[18,19]$. The subjects were provided with an exercise books to record the quantity and quality of exercise each day. The exercise improvement and the details of any problems were discussed each time.

Control Period (week -4 to 0 ): The subjects could not have participated in any exercise programs or any kind of systematized trainings.

Intervention Period (week 0 to 6): The subjects were instructed to perform the sit to stand by using the Sit to Stand Trainer without hands as possible. The researchers adjusted the seat height as subject's knees height and adjusted the weight support at $50 \%$ of subject's body weight. The subjects started with 10 repetitions of sit to stand and they were instructed to increase by 5 as they were able, until each of them reached the number of repetitions exercise for elderly with a maximum of 50 repetitions [20]. All the subjects performed over 6 weeks ( 5 days a week; Monday to Friday).

\section{Statistics analysis}

Paired samples T-tests was used to measure the difference before and after of each test in each period.

\section{Results and discussion in outcome measurement tests evaluation}

Table 5 presents physical outcome measurement tests in week -4 and 0 . The results show significant decrease in BBS $(P=0.000)$ and 4-meter Gait Speed Test $(\mathrm{P}=0.000)$. These results show that elderly without exercise in 4 weeks can decrease balance and gait speed. However, there is a significant increase in 30-second Chair Stand Test $(\mathrm{P}=0.05)$, though, the mean of numbers of sit to stand had increased approximately to 1 . Likewise, there is no significant difference in $15-\mathrm{cm}$ Step Test $(\mathrm{P}=0.408)$, though, the scores had decreased. This show that elderly without exercise in 4 weeks might not always decrease strength and aerobic capacity. 
http://wjst.wu.ac.th

Table 5 Mean and standard deviations of the outcome measurement tests between week -4 and week 0 (n $=27)$.

\begin{tabular}{lccccc}
\hline \multirow{2}{*}{ Physical outcome measurement tests } & \multicolumn{2}{c}{ Week -4 } & \multicolumn{2}{c}{ Week 0 } & \multirow{2}{*}{ P value } \\
\cline { 2 - 5 } & Mean & SD & Mean & SD & \\
\hline BBS (scores) & 33.41 & 7.28 & 23.22 & 3.9 & $\mathbf{0 . 0 0 0}$ \\
15 cm Step Test (ml/kg/min) & 51.81 & 12.36 & 49.63 & 12.43 & 0.408 \\
30 s Chair Stand Test (times) & 13.59 & 2.98 & 15 & 3.2 & $\mathbf{0 . 0 5 *}$ \\
4 m Gait Speed Test (s) & 2.88 & 0.43 & 3.26 & 0.51 & $\mathbf{0 . 0 0 0 *}$ \\
\hline
\end{tabular}

*Significant at $\mathrm{P} \leq 0.05$

Table 6 presents physical outcome measurement tests in week 0 and 6 which shows significant improvement in BBS Test $(\mathrm{P}=0.000), 30$-second Chair Stand Test $(\mathrm{P}=0.001)$ and $4 \mathrm{~m}$ Gait Speed Test $(\mathrm{P}=0.000)$. This study also finds that a short period of minimal help in sit-to-stand training can progress in balance, strength, and gait speed. The improvement in BBS score is similar to the 6 months of highintensity of functional training [21]. Sit to stand is a whole-body action, requiring body mass control and other sensorimotor systems including strength and agility [22]. Therefore, repetitions of sit-to-stand could improve results on physical outcome measurements. This study may be clinically significant in place of reduced falls risk. However, training with Sit to Stand Trainer in 6 weeks is no significant difference in $15 \mathrm{~cm}$ Step Test $(\mathrm{P}=0.586)$ which shows that this intervention program may not suitable to improve aerobic capacity among the elderly. Thus, future research for aerobic capacity should increase the repetition, duration or intensity such as decrease the support level of the device or extent the intervention period or combined an anaerobic training program.

Table 6 Mean and standard deviations of the outcome measurement tests between week 0 and week 6 (n $=27)$.

\begin{tabular}{|c|c|c|c|c|c|}
\hline \multirow{2}{*}{ Physical outcome measurement tests } & \multicolumn{2}{|c|}{ Week 0} & \multicolumn{2}{|c|}{ Week 6} & \multirow{2}{*}{$P$ value } \\
\hline & Mean & SD & Mean & SD & \\
\hline BBS (scores) & 23.22 & 3.9 & 46.04 & 6.75 & $0.000 *$ \\
\hline $15 \mathrm{~cm}$ Step Test (ml/kg/min) & 49.63 & 12.43 & 48.89 & 11.74 & 0.586 \\
\hline 30 s Chair Stand Test (times) & 15 & 3.2 & 17.63 & 2.39 & $0.001 *$ \\
\hline 4 m Gait Speed Test (s) & 3.26 & 0.51 & 2.37 & 0.43 & $0.000 *$ \\
\hline
\end{tabular}

*Significant at $\mathrm{P} \leq 0.05$ 
http://wjst.wu.ac.th

\section{Conclusions}

The Sit to Stand Trainer promotes natural movement in kinematics (similarity in trunk, hip, knee and ankle angles, including trunk, hip, knee and ankle angular velocities and speed and distance of head) which reduces the body weight that contacted to the ground (decreasing in kinetics - rising and peak of vGRFs during the start phase and rising phase). This helps the users to stand up easier. The results of this study could inform therapists to possibly consider this device for training in clinical practice. Furthermore, 6 weeks of training with Sit to Stand Trainer could improve muscle strength, balance and gait speed among elderly.

\section{Acknowledgements}

The authors gratefully acknowledge the financial support from Integrated Research and Innovation Funding Program 2017, National Research Council of Thailand, and Excellence Center in Creative Engineering Design and Development. The financial sponsors played no role in the design, execution, analysis and interpretation of data or in writing the study for publication.

\section{References}

[1] JD Moreland, JA Richardson, CH Goldsmith and CM Clase. Muscle weakness and falls in older adults: A systematic review and meta-analysis. J. Am. Geriat. Soc. 2004; 52, 1121-9.

[2] P Laukkanen, E Heikkinen and M Kauppinen. Muscle strength and mobility as predictors of survival in 75-84-year-old people. Age Ageing 1995; 24, 468-73.

[3] O Seynnes, MAF Singh, O Hue, P Pras, P Legros and PL Bernard. Physiological and functional responses to low-moderate versus high-intensity progressive resistance training in frail elders. $J$. Gerontol. A Biol. Sci. Med. Sci. 2004; 59, 503-9.

[4] NK Latham, CS Anderson, A Lee, DA Bennett, A Moseley and ID Cameron. A randomized controlled trial of quadriceps resistance exercise and vitamin $\mathrm{d}$ in frail older people: The frailty interventions trial in elderly subjects. J. Am. Geriat. Soc. 2003; 51, 291-9.

[5] A Kralj, RJ Jaeger and M Munih. Analysis of standing up and sitting down in humans: Definitions and normative data presentation. J. Biomech. 1990; 23, 1123-38.

[6] PT Cheng, CL Chen, CM Wang and WH Hong. Leg muscle activation patterns of sit-to-stand movement in stroke patients. Am. J. Phys. Med. Rehabil. 2004; 83, 10-6.

[7] JM Burnfield, B McCrory, Y Shu, TW Buster, AP Taylor and AJ Goldman. Comparative kinematic and electromyographic assessment of clinician- and device-assisted sit-to-stand transfers in patients with stroke. Phys. Ther. 2013; 93, 1331-41.

[8] SK Banala, SH Kim, SK Agrawal and JP Scholz. Robot assisted gait training with active leg exoskeleton (ALEX). IEEE Trans. Neural. Syst. Rehabil. Eng. 2009; 17, 2-8.

[9] G Kwakkel, BJ Kollen and HI Krebs. Effects of robot-assisted therapy on upper limb recovery after stroke: A systematic review. Neurorehabil. Neural. Repair. 2008; 22, 111-21.

[10] TG Hornby, DD Campbell, JH Kahn, T Demott, JL Moore and HR Roth. Enhanced gait-related improvements after therapist-versus robotic-assisted locomotor training in subjects with chronic stroke: A randomized controlled study. Stroke 2008; 39, 1786-92.

[11] JK Veneman, R Kruidhof, EEG Hekman, R Ekkelenkamp, EHFV Asseldonk and HVD Kooij. Design and evaluation of the LOPES exoskeleton robot for interactive gait rehabilitation. IEEE Trans. Neural. Syst. Rehabil. Eng. 2007; 15, 379-86.

[12] BE Gray. Slips, Stumbles, and Falls: Pedestrian Footwear and Surfaces. Vol. 1103. ASTM International, Pennsylvania, 1990, p. 1-162.

[13] M Fujimoto and L Chou. Dynamic balance control during sit-to-stand movement: An examination with the center of mass acceleration. J. Biomech. 2012; 45, 543-8.

[14] YC Pai, BJ Naughton, RW Chang and MW Rogers. Control of body centre of mass momentum during sit-to-stand among young and elderly adults. Gait Posture 1994; 2, 109-16. 
http://wjst.wu.ac.th

[15] R Nozawai and S Yamamoto. The relationship of lower limb and trunk movements in sit-to-stand performed by the young and elderly. J. Phys. Ther. Sci. 2012; 27, 31-5.

[16] CA Stevermer and JC Gillette. Kinematic and kinetic indicators of sit-to-stand. J. Appl. Biomech. 2016; 32, 7-15.

[17] Z Matjacic, M Zadravec and J Oblak. Sit-to-stand trainer: An apparatus for training "normal-like" sit to stand movement. IEEE Trans. Neural. Syst. Rehabil. Eng. 2016; 24, 639-49.

[18] V Cavani, CM Mier, AA Musto and N Tummers. Effects of a 6-week resistance-training program on functional fitness of older adults. J. Aging Phys. Act. 2002; 10, 443-52.

[19] CM Dean, CL Richards and F Malouin. Task-related circuit training improves performance of locomotor tasks in chronic stroke: A randomized, controlled pilot trial. Arch. Phys. Med. Rehabil. 2000; 81, 409-17.

[20] J Rosie and D Taylor. Sit-to-stand as home exercise for mobility-limited adults over 80 years of age-GrandStand system may keep you standing? Age Ageing 2007; 36, 555-62.

[21] E Rosendahl, N Lindelöf, H Littbrand, E Yifter-Lindgren, L Lundin-Olsson, L Haglin, Y Gustafson and L Nyberg. High-intensity functional exercise program and protein enriched energy supplement for older persons dependent in activities of daily living: A randomised controlled trial. Aust. J. Physiother. 2006; 52, 105-13.

[22] SR Lord, SM Murray, K Chapman, B Munro and A Tiedemann. Sit to-stand performance depends on sensation, speed, balance, and psychological status in addition to strength in older people. $J$. Gerontol. A Biol. Sci. Med. Sci. 2002; 57, 539-43. 